\title{
Characteristics of $\mathrm{Au} / \mathrm{HMS}$ catalysts for selective oxidation of benzyl alcohol to benzaldehyde
}

\author{
Chun Yan Ma, Jie Cheng, Hai Lin Wang, Qin Hu, Hua Tian, Chi He, Zheng Ping Hao* \\ State Key Laboratory of Environmental Chemistry and Ecotoxicology, Research Center for Eco-Environmental Sciences, Chinese Academy of Sciences,
} 18 Shuangqing Road, Haidian District, Beijing 100085, PR China

\section{A R T I C L E I N F O}

\section{Article history:}

Available online 19 June 2010

\section{Keywords:}

Gold

Mesoporous HMS

Characteristics

Selective oxidation

Benzyl alcohol

\begin{abstract}
A B S T R A C T
Au/HMS catalysts are prepared by impregnation method and direct synthesized method and evaluated for the selective oxidation of benzyl alcohol. Among all the catalysts studied, Au/HMS catalyst prepared by impregnation method exhibits the best activity, the benzyl alcohol conversion of $42.9 \%$ and benzaldehyde selectivity of $95 \%$ can be achieved at $80{ }^{\circ} \mathrm{C}, 1 \mathrm{~atm} \mathrm{O}_{2}$ and existence of $\mathrm{Na}_{2} \mathrm{CO}_{3}$ aqueous solution. The $\mathrm{Au} / \mathrm{HMS}$ catalysts are characterized by low-angle X-ray diffraction (XRD), wide-angle XRD, $\mathrm{N}_{2}$ adsorption/desorption and transmission electron microscopy (TEM) techniques. The effects of prepared method, gold particle size and HMS structure are investigated in detail. The active phase of gold catalysts for selective oxidation of benzyl alcohol is explored based on the catalytic performance and characterization results. Moreover, the possible activation mechanism for selective oxidation of benzyl alcohol on Au/HMS catalysts is studied by means of $\mathrm{CO}$ and $\mathrm{O}_{2}$ adsorption in situ diffuse reflectance Fourier transform infrared spectroscopy (DRIFTS).
\end{abstract}

(C) 2010 Elsevier B.V. All rights reserved.

\section{Introduction}

The aerobic oxidation of alcohols to their corresponding aldehydes and ketones is of interest for both economic and environmental reasons [1]. Traditionally, manganese [2] and chromium salts [3] have been used as stoichiometric oxidants in this process. These materials are not only expensive but also have serious toxicities. Several homogenous Pd [4-6], $\mathrm{Cu}[7,8]$ or $\mathrm{Ru}$ [9-11] catalysts are able to serve for the selective oxidation of alcohols, but they require the use of organic solvents or high-pressure oxygen. The present stringent ecological standards have forced researchers to develop new environmental friendly methods. So far, small-crystal-size gold supported on inorganic oxides or active carbon has recently attracted considerable attention since these catalysts are able to promote the selective oxidation of alcohols [12-18]. Thus, from a fundamental study of view, as well as from a technical aspect, gold catalysis is a topic of intense scientific interest and draws attentions from diverse research groups.

So far mesoporous inorganic oxides are of interest because they exhibit numerous edges and corners for adsorption of reactants and dispersion of noble metal nanoparticles $[5,19]$. HMS silicas, form a spongelike particle texture through the intergrowth of mesoscopic wormhole framework domains, and have found promising

\footnotetext{
* Corresponding author. Tel.: +8610 62923564; fax: +861062923564

E-mail address: zpinghao@rcees.ac.cn (Z.P. Hao).
}

applications as heterogeneous catalysts and as supports for the immobilization of reagents [20]. A simple method for tailoring the framework pore size of HMS materials in the presence of a single amine surfactant could make them even more attractive for such applications. Consequently, the framework sites of HMS silicas are generally more accessible for metal ion trapping and chemical catalysis in comparison to their hexagonal SBA-15 and MCM-41 counterparts with the same framework pore size, but with highly monolithic particle morphologies [21]. Thus, HMS silicas prepared with dodecylamine as template were selected as catalyst support.

These selective oxidation of alcohol reactions with supported gold catalysts allow an oxidation by molecular oxygen, thus are a beautiful example of "green" chemistry [22]. However, the base presence was found to be essential for reaction activity under mild conditions (e.g. lower temperature or atmospheric pressure). It is considered to be essential for the first hydrogen abstraction, and this is a significant difference between Pd and Pt catalysts, which are effective in acidic as well as basic conditions [22,23]. Therefore, the activity of organic solvent free liquid phase oxidation of benzyl alcohol with $\mathrm{Na}_{2} \mathrm{CO}_{3}$ solution (as promoter) is investigated in this work.

In the mechanism investigation of supported gold catalysts, $\mathrm{Au} / \mathrm{CeO}_{2}$ catalysts for selective oxidation of alcohol were reported by Abad et al. [17,18], in which $\mathrm{CeO}_{2}$ contained stoichiometric oxidation sites of alcohols, and the existence of cationic gold was good for the reaction, it is on cationic gold that intermediate metal hydrides transfers reversibly. Kung et al. [24] proposed the model 
for $\mathrm{CO}$ oxidation, suggesting the active site consists of Au atoms and a cationic $\mathrm{Au}^{+}$species with neighboring $\mathrm{OH}$ group. In an investigation by Rossi and co-workers [25] showed that a two-electron mechanism for selective oxidation of glucose with gold catalyst. The hydrogen peroxide decomposed because of the basic medium before it reaches a concentration at which it would efficiently compete with oxygen as the oxidant. However, a detailed mechanism of alcohol oxidation on Au nanoparticles is still not clear yet.

Herein, we present the synthesis and characterization of $\mathrm{Au} / \mathrm{HMS}$ catalysts and their evaluation for selective oxidation of benzyl alcohol by use of molecular oxygen. The Au/HMS catalyst prepared by impregnation method has proved to be effective for selective and environmentally benign benzyl alcohol oxidation. We also mention the influenced effects such as gold particle size and structure of HMS on the catalytic activities. Furthermore, the general reaction mechanism of $\mathrm{Au} / \mathrm{HMS}$ catalysts for selective catalytic oxidation of benzyl alcohol is discussed.

\section{Experimental}

\subsection{Catalyst preparations}

\subsubsection{Direct synthesized method}

Dissolving $0.5 \mathrm{~g}$ dodecylamine (DDA) into $4.18 \mathrm{~g}$ ethanol and diluting the solution to $5.33 \mathrm{~g}$ water. $0.3 \mathrm{ml} \mathrm{HAuCl}_{4}$ $(16.76 \mathrm{mg} \mathrm{Au} / \mathrm{ml})$ precursor was added to the surfactant solution under vigorous stirring for $2 \mathrm{~h}$ and a homogeneous mixture was obtained. The resulting homogeneous mixture contained gold nanoparticles protected by DDA $2.08 \mathrm{~g}$ tetraethylorthosilicate (TEOS) was added into the homogeneous mixture. The reaction solution was stirred at ambient temperature for $18 \mathrm{~h}$ in a flask. The obtained solid was washed with distilled water, and dried at $70^{\circ} \mathrm{C}$ for $5 \mathrm{~h}$. The solid was extracted by ethanol for $24 \mathrm{~h}$ to remove the surfactant DDA, followed by drying at $70^{\circ} \mathrm{C}$ for $5 \mathrm{~h}$. Subsequently, the sample was calcined at $300^{\circ} \mathrm{C}$ for $2 \mathrm{~h}$. The synthesized Au/HMS catalyst was named as AuH0.5. The theoretical loading of gold in AuH0.5 was about $0.5 \%$. When $0.6 \mathrm{ml}$ or $0.9 \mathrm{ml} \mathrm{HAuCl}_{4}$ solution was used according to the preparation process of AuH0.5, the obtained $\mathrm{Au} / \mathrm{HMS}$ catalyst was name as AuH1.0 and AuH1.5, respectively. The theoretical loading of gold in AuH1.0 and AuH1.5 was about 1.0 and $1.5 \%$, respectively.

\subsubsection{Impregnation method}

Dissolving $0.5 \mathrm{~g}$ DDA into $4.18 \mathrm{~g}$ alcohol and diluting the solution to $5.33 \mathrm{~g}$ water. $2.08 \mathrm{~g}$ TEOS was added into the solution and stirred at ambient temperature for $18 \mathrm{~h}$ in a flask. The obtained solid was washed with distilled water, dried at $70^{\circ} \mathrm{C}$ for $5 \mathrm{~h}$ and calcined at $600^{\circ} \mathrm{C}$ for $4 \mathrm{~h}$. The resulting white powder was HMS. $1 \mathrm{M}$ sodium hydroxide solution was added into the chloroauric acid solution ( $17.6 \mathrm{mg} \mathrm{Au} / \mathrm{ml}, 0.6 \mathrm{ml}$ ) for adjusting the solution $\mathrm{pH}$ to 7 . Then $1.0 \mathrm{~g}$ of HMS powder was added and aged at room temperature for $12 \mathrm{~h}$. The precipitates were washed several times, dried at $70^{\circ} \mathrm{C}$ for $5 \mathrm{~h}$ and calcined at $300^{\circ} \mathrm{C}$ for $2 \mathrm{~h}$. The obtained Au/HMS sample was named as IMAuH. The theoretical loading of gold in IMAuH was about $1.0 \%$.

\subsection{Catalyst characterizations}

The actual gold content in the samples was determined by Inductively Coupled Plasma Optical Emission Spectrometer (ICPES) OPTIMA 2000. Before the measurements were taken, the solid sample was dissolved in aqua regia. Transmission electron microscopy (TEM) analysis was conducted using H-7500 microscope operating with an acceleration voltage of $80 \mathrm{kV}$. The specimens were prepared by ultrasonication in ethanol, evaporating a drop of the resultant suspension onto a carbon support

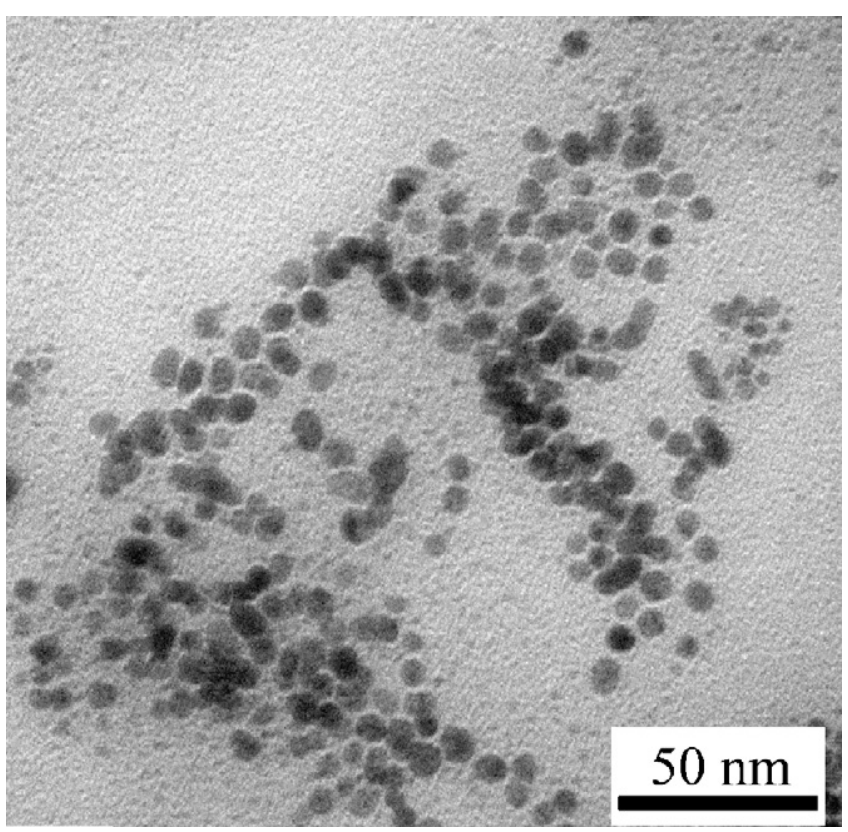

Fig. 1. TEM image of gold nanoparticles protected by DDA.

grid. Low-angle X-ray powder diffraction (XRD) was recorded on a Rigaku TTR2 powder diffraction system using $\mathrm{Cu} K \alpha$ radiation in the $2 \theta$ range of $0.7-6.0^{\circ}$ with a scanning step size of $0.02^{\circ}$. Wide-angle XRD patterns were measured on a Rigaku TTR2 powder diffractometer using $\mathrm{Cu} \mathrm{K} \alpha$ radiation $(\lambda=0.15418 \mathrm{~nm})$ in the $2 \theta$ range of $10-80^{\circ}$ with a scanning rate of $4{ }^{\circ} \mathrm{min}^{-1}$. The textural properties of the samples were measured by $\mathrm{N}_{2}$ adsorption/desorption at liquid nitrogen temperature, using a gas adsorption analyzer NOVA 1200. All samples were outgassed for $5 \mathrm{~h}$ at $200^{\circ} \mathrm{C}$ prior to adsorption. Gas adsorption was performed using nitrogen as the adsorbate at liquid nitrogen temperature. Infrared spectra of the samples were recorded on Bruker Tensor27 using DRIFT technique, scanned from 4000 to $800 \mathrm{~cm}^{-1}$, with 256 scans at a resolution of $4 \mathrm{~cm}^{-1}$. Gas mixtures $\left(2 \% \mathrm{CO}+10 \% \mathrm{O}_{2}\right.$ in $\mathrm{He}$ ) were prepared using mass flow controllers and using a gas flow of $25 \mathrm{ml} \mathrm{min}^{-1}$ passing through the catalyst bed at $25^{\circ} \mathrm{C}$. After holding this temperature for $10 \mathrm{~min}$, it was stepwise increased to the next designed temperature.

\subsection{Activity measurement of catalyst}

A mixture of $\mathrm{Na}_{2} \mathrm{CO}_{3}$ aqueous solution $\left(0.55 \mathrm{moll}^{-1}, 25 \mathrm{ml}\right)$, $0.05 \mathrm{ml}$ decane (use as external standard) and $0.2 \mathrm{~g}$ of catalyst was prepared in a high-pressure reactor. The $0.5 \mathrm{ml}$ of benzyl alcohol was then added into the solution and the resulting mixture was stirred at $80^{\circ} \mathrm{C}$ with a stirring speed of $600 \mathrm{rpm}$ for $2 \mathrm{~h}$ under $1 \mathrm{~atm}$ of $\mathrm{O}_{2}$. After the reaction, the catalyst was removed from the reaction mixture by centrifugation; the products and the unconverted reactants were analyzed by gas chromatography with a flame ionization detector, using a HP-5 column. Average TOF for the oxidation of benzyl alcohol for the initial $2 \mathrm{~h}$ of reaction is calculated on the basis of ratio of moles of benzaldehyde per mole of Au per hour.

\section{Results and discussion}

\subsection{Catalyst preparation and characterizations}

As-synthesized gold nanoparticles were prepared by dissolve the $\mathrm{HAuCl}_{4}$ aqueous solution in the ethanol solution of DDA. Typical TEM picture of the as-synthesized Au nanoparticles is shown in Fig. 1. The Au nanoparticles exhibit pseudospherical particles and 

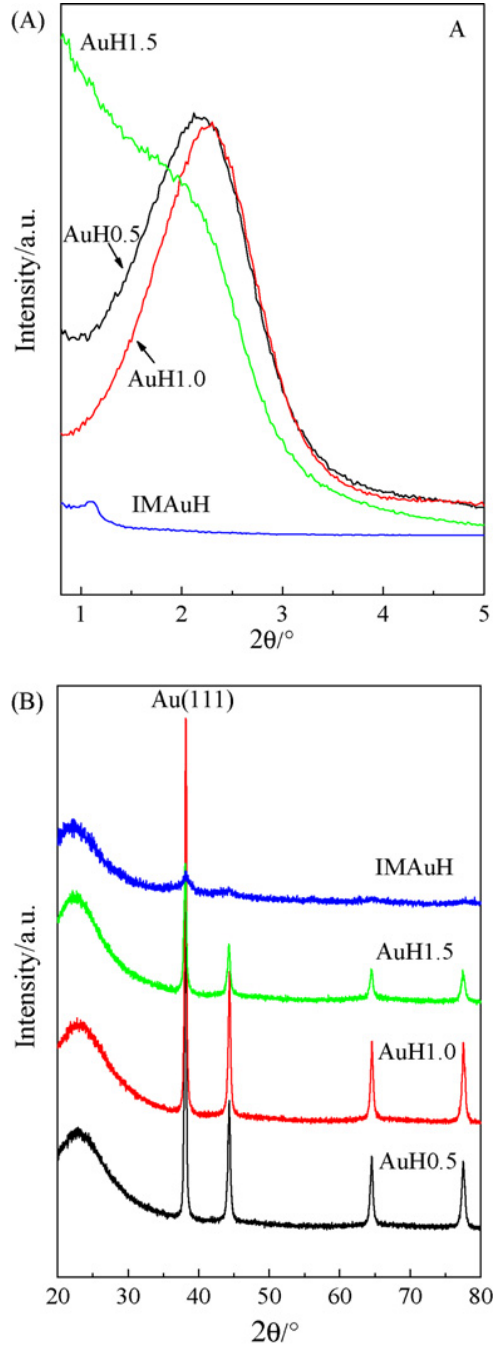

Fig. 2. (A) Low-angle and (B) wide-angle XRD patterns of Au/HMS materials.

these Au nanoparticles show a broad size distribution ranged from 2 to $15 \mathrm{~nm}$. The Au particles were not monodisperse and agglomeration partially.

Fig. 2A provides the low-angle XRD patterns for the $\mathrm{Au} / \mathrm{HMS}$ prepared by two methods. Each sample exhibited a single low-angle reflection indicative of the average pore-pore correlation distance [25]. The $d_{100}$ and lattice parameter $a$ of these samples are given in Table 1 . The pore-pore correlation distance $d_{100}$ of IMAuH is $8.0 \mathrm{~nm}$, larger than the AuH0.5, AuH1.0 and AuH1.5, which are $4.1,3.8$ and $4.3 \mathrm{~nm}$, respectively. The increase of the pore-pore correlation distance for IMAuH is due to the relatively higher $\mathrm{pH}$ value in self-assembly process of HMS. The loss of a well-expressed pore-pore correlation peak indicated that the wormhole framework structure is largely lost on AuH1.5. The $d_{100}$ is shifted to
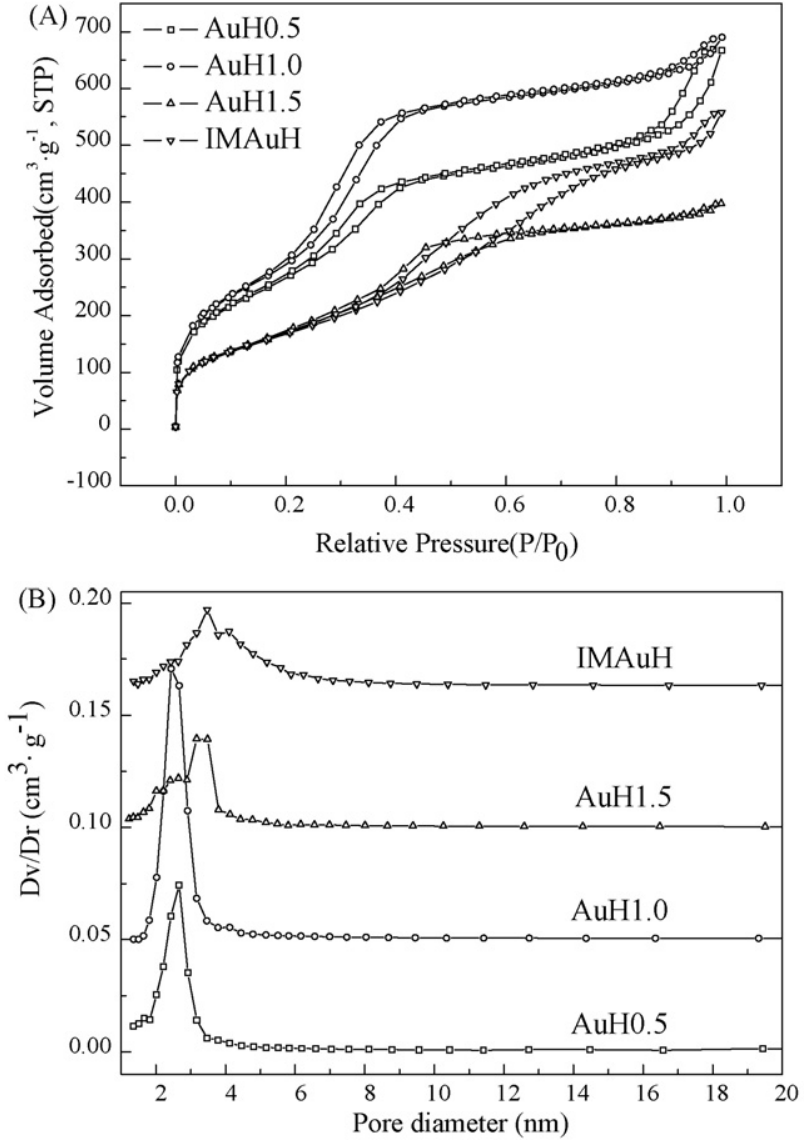

Fig. 3. $\mathrm{N}_{2}$ adsorption/desorption isotherms (A) and pore size distribution (B) calculated from desorption branch of Au/HMS materials.

higher value, indicating that a lattice expansion and an increase of the pore diameter occurred [25].

The wide-angle XRD patterns of Au/HMS materials are shown in Fig. 2B. The presence of characteristic diffraction lined at $2 \theta=38.2^{\circ}$, which can be assigned to the (111) planes of face centered cubic structure of gold, indicating that gold had crystallized [26]. The broader the $\mathrm{Au}(111)$ peak, the smaller average particle size. The sharp Au(1 11 ) peak of AuH1.0 and AuH0.5 suggested a large average gold particle size, larger than $25 \mathrm{~nm}$ calculated by Scherrer equation. The average gold particle size of AuH1.5 is about $10 \mathrm{~nm}$ deduced from the reflection $\mathrm{Au}(111)$ peak. The IMAuH catalyst had relatively weaker diffraction lines for gold, indicating that gold agglomerates were low in the HMS. The average size of the gold particles of IMAuH is about $5 \mathrm{~nm}$.

Fig. $3 \mathrm{~A}$ and $\mathrm{B}$ shows $\mathrm{N}_{2}$ adsorption/desorption isotherms and pore size distributions, respectively, for Au/HMS samples. The pore structure parameters, such as the specific area $\left(S_{\mathrm{BET}}\right)$, pore volume $(V)$ and pore diameter $\left(D_{\mathrm{BJH}}\right)$ of all samples are listed in Table 1 . The specific area decreased as the following order:

Table 1

The structural parameters of Au/HMS materials.

\begin{tabular}{|c|c|c|c|c|c|c|}
\hline Catalyst & Au content (\%) & $d_{100}(\mathrm{~nm})$ & $a(\mathrm{~nm})$ & $S_{\text {BET }}\left(\mathrm{m}^{2} \mathrm{~g}^{-1}\right)$ & $V\left(\mathrm{~cm}^{3} \mathrm{~g}^{-1}\right)$ & $D_{\mathrm{BJH}}(\mathrm{nm})$ \\
\hline $\operatorname{ImAuH}$ & 0.95 & 8.0 & 9.3 & 595 & 0.863 & $3.45 / 4.09$ \\
\hline AuH0.5 & 0.41 & 4.1 & 4.7 & 949 & 1.032 & 2.64 \\
\hline AuH1.0 & 0.89 & 3.8 & 4.4 & 1046 & 1.067 & 2.42 \\
\hline AuH1.5 & 1.32 & 4.3 & 5.0 & 602 & 0.614 & $2.56 / 3.34$ \\
\hline
\end{tabular}

a Gold content measured by ICP-ES. $d_{100}$ : the interplanar spacing of the (100) plane. $a$ : the lattice parameter calculated by $a=2 d_{1}$ oo $/ \sqrt{3}$. $S_{\mathrm{BET}}$ : BET surface area calculated

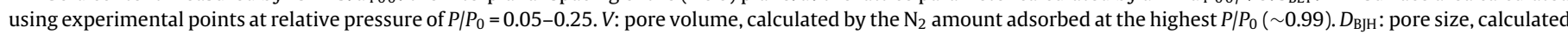
by BJH method. 

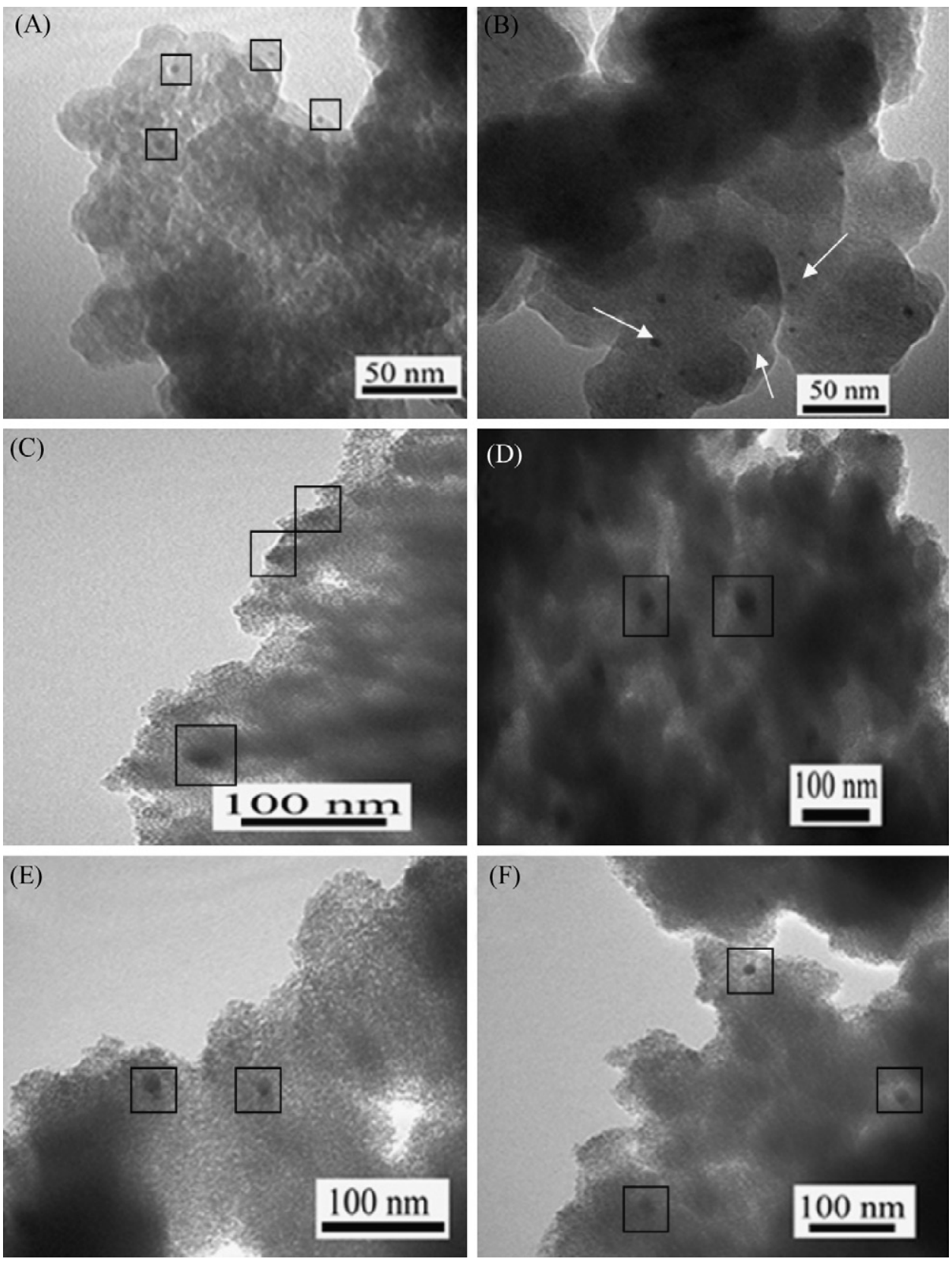

Fig. 4. TEM images of Au/HMS materials: (A and B) IMAuH, (C) AuH0.5, (D) AuH1.0 and (E and F) AuH1.5.

AuH1.0 > AuH0.5 > AuH1.5 > IMAuH. The large losing of wormhole framework structure contributed to the low specific area of AuH1.5. The adsorption/desorption isotherms of the Au/HMS samples have the shape of type IV isotherm according to the IUPAC classification [27], with a sharp step at intermediate relative pressures. The appreciable type $\mathrm{H} 1$ hysteresis loops indicate the presence of textural mesopores [28]. All the samples except AuH1.5 show two capillary condensation steps. The first hysteresis loops for AuH0.5 and AuH1.0 start at partial pressure of about $0.25-0.45$, indicating the presence of framework mesoporosity. The second hysteresis loops start at partial pressure of about $0.80-1.00$ is due to textural interparticle mesoporosity or macroporosity. The capillary pore filling of the IMAuH sample starts at higher pressure than the capillary pore filling in the AuH1.0 sample, in agreement with the observed larger pore diameter of the IMAuH sample (Fig. 3B). The absence of second hysteresis loop of AuH1.5 indicates that the partial losing of uniform textural porosity.
Fig. 4 shows the TEM images of the Au/HMS materials. The dark spots presented in Fig. 4A-F were recognized as gold particles. The formation of small gold particles on IMAuH sample was observed when impregnation method used. The gold particles are about $5 \mathrm{~nm}$ and distribute relatively uniform for IMAuH (Fig. 4A and B). Large gold particles are presented in Fig. $4 \mathrm{C}$ and D. For the $\mathrm{HAuCl}_{4}$ solution was dealt with the ethanol solution of template DDA in the synthesis of AuH0.5, it was observed that gold particles exhibited the analogous wormhole framework like HMS. Gold particles of AuH1.0 aggregated and appeared larger than $25 \mathrm{~nm}$. The size of gold particles of AuH1.5 is smaller than AuH1.0, which is about $10 \mathrm{~nm}$. This is in accordance with the results of wide-angle XRD (Fig. 2B).

Fig. 5A displays the temperature-resolved DRIFT spectra of AuH1.0 under the stream of $\mathrm{CO}+\mathrm{O}_{2}+\mathrm{He}$ mixture. The band at $2170-2190 \mathrm{~cm}^{-1}$ is typically attributed to the adsorption of CO on the support oxide $[29,30]$. Therefore, the absorption band at $2174 \mathrm{~cm}^{-1}$ was assigned to the adsorption of CO on HMS. The 

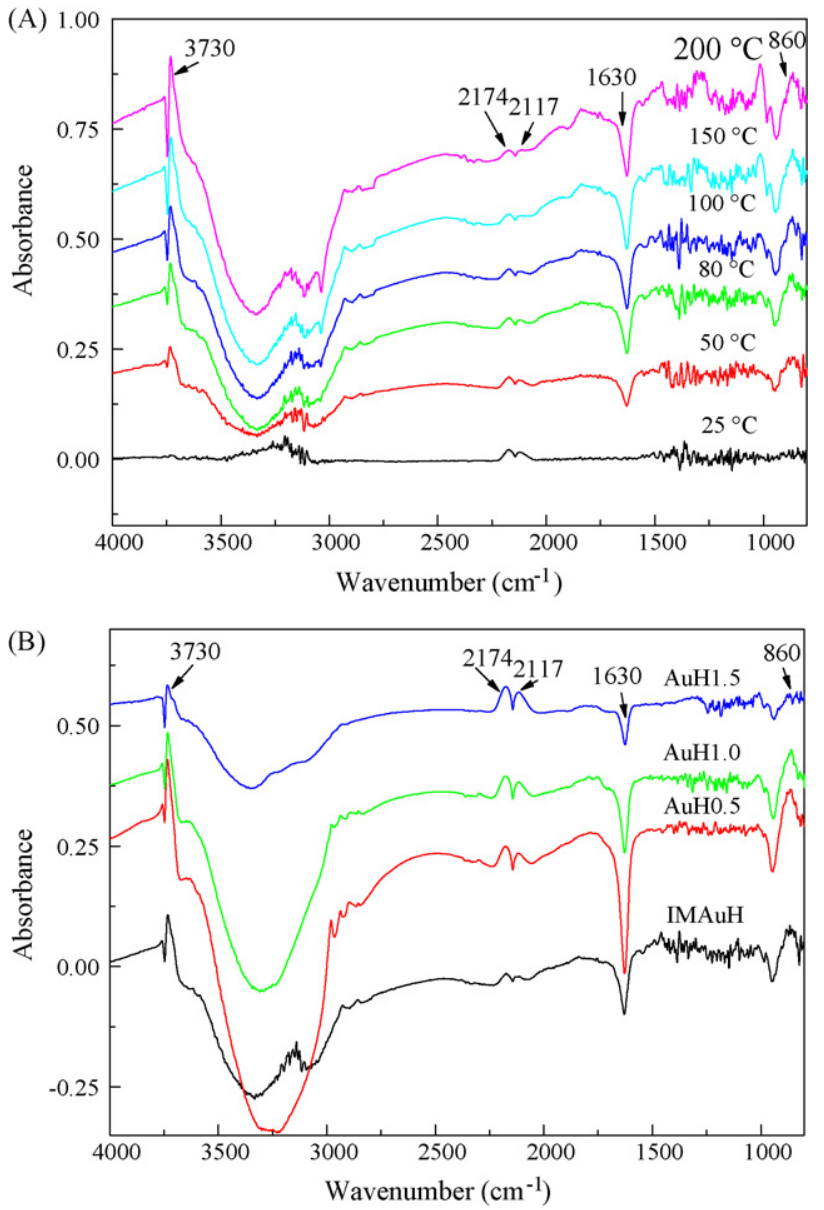

Fig. 5. Steady-state temperature-resolved DRIFT spectra of AuH1.0 recorded under $\mathrm{CO}+\mathrm{O}_{2}+$ He mixture (A) and DRIFT spectra of a series of Au/HMS samples recorded under $\mathrm{CO}+\mathrm{O}_{2}+\mathrm{He}$ mixture at $80^{\circ} \mathrm{C}(\mathrm{B})$.

absorption intensity at $2117 \mathrm{~cm}^{-1}$ is attributed to $\mathrm{CO}$ on $\mathrm{Au}^{0}$ [29-32]. It is noticed that the intensities of the absorption band at 2117 and $2173 \mathrm{~cm}^{-1}$ decreased with the temperature. It indicated that the $\mathrm{CO}$ adsorption on $\mathrm{Au}^{0}$ and HMS was to weaken with the temperature. The absorption band at $1630 \mathrm{~cm}^{-1}$ was attributed to the bending vibrations of adsorbed $\mathrm{H}_{2} \mathrm{O}$ [33]. The higher temperature of reaction system, the more negative deformational vibrations of adsorbed water molecules at ca. $1630 \mathrm{~cm}^{-1}$ were observed. It indicated that $\mathrm{H}_{2} \mathrm{O}$ is consumed during the reaction process. The absorption intensity of the inert $\mathrm{OH}$ groups on HMS at about $3730 \mathrm{~cm}^{-1}$ increased with the temperature [34]. It is worth noticing that the absorption band at $860 \mathrm{~cm}^{-1}$ was attributed to the peroxide species. They may be the ozonide reaction intermediate generated from the reaction of gaseous $\mathrm{O}_{2}$ with surface $\mathrm{O}^{-}$from OH decomposition [34].

Fig. 5B DRFIT spectra of Au/HMS samples recorded under $\mathrm{CO}+\mathrm{O}_{2}+\mathrm{He}$ mixture at $80^{\circ} \mathrm{C}$. The absorption intensities at 2117 and $2174 \mathrm{~cm}^{-1}$ for $\mathrm{CO}$ on $\mathrm{Au}^{0}$ and HMS, respectively, was weaker for IMAuH sample. The absorption at $860 \mathrm{~cm}^{-1}$ was weaker for AuH1.5 sample, indicating less surface $\mathrm{O}^{-}$species decomposed from $\mathrm{OH}$ groups.

\subsection{Catalyst evaluation for the oxidation of benzyl alcohols}

The selective oxidation of benzyl alcohol over Au/HMS catalysts was investigated in the absence of base media. The Au/HMS catalysts hardly have catalytic activity. Au/HMS catalysts were initially investigated for oxidation of benzyl alcohol at $80^{\circ} \mathrm{C}$ with oxygen
Table 2

Selective oxidation of benzyl alcohol to benzaldehyde catalyzed by Au/HMS.

\begin{tabular}{llcl}
\hline Catalyst & Conversion (\%) & Selectivity (\%) & TOF $\left(\mathrm{h}^{-1}\right)$ \\
\hline IMAuH & 42.9 & 95 & 98 \\
AuH0.5 & 13.4 & 92 & 60 \\
AuH1.0 & 19.9 & $>99$ & 48 \\
AuH1.5 & 10.2 & 83 & 14 \\
\hline
\end{tabular}

Results were obtained for the oxidation of benzyl alcohol after $2 \mathrm{~h}$ of reaction. Conversion and selectivity were determined by GC using decane as external standards. Benzyl alcohol (0.5 ml), Au/HMS (0.2 g), $\mathrm{H}_{2} \mathrm{O}(25 \mathrm{ml}), \mathrm{Na}_{2} \mathrm{CO}_{3}(1.457 \mathrm{~g}), 80^{\circ} \mathrm{C}$, $p=1 \mathrm{~atm} \mathrm{O}_{2}$. TOF was measured after first $2.0 \mathrm{~h}$ of reaction.

as oxidant in the existence of base media. Their catalytic performances are listed in Table 2. The IMAuH catalyst led to a turnover frequency (TOF) of 98 and the selectivity to benzyldehyde was 95\%. The AuH1.0 was less active than IMAuH for benzyl alcohol oxidation and the TOF reached to 48 in $2 \mathrm{~h}$ with the selectivity increasing to $99 \%$. For the AuH0.5 catalysts, a conversion rate of $13.4 \%$ was observed which corresponded to a TOF of 60 , higher than the TOF of AuH1.0, while the selectivity to benzyldehyde reduced to $92 \%$. TOF decreased to 14 when the AuH1.5 used, and the selectivity also reduced to $83 \%$. The AuH1.5 gave the worst activity and selectivity of selective oxidation of benzyl alcohol among the series of Au/HMS catalysts.

\subsection{Mechanistic investigations}

Au catalysts were prepared by two different methods. The actual gold loading was analyzed for all Au/HMS catalysts and the actual gold loading is close to the theoretic gold loading (Table 1). In impregnation method, the $\mathrm{Au}(\mathrm{OH})_{3} \mathrm{Cl}^{-}$complex produced by adjusting the $\mathrm{pH}$ value of $\mathrm{HAuCl}_{4}$ solution to 7 , in order to obtain a high dispersion of $\mathrm{Au}$ in the final catalyst [22]. In direct synthesis of Au/HMS catalysts, 2-15 nm gold nanoparticles capped by DDA were obtained at the beginning. However, gold particles grew bigger in the process of self-assembly pathway of HMS framework structures. In this paper, the gold particles of Au/HMS prepared by impregnation method were smaller than direct synthesized method. Consequentially, the activity of IMAuH is higher than the activity of AuH0.5, AuH1.0 and AuH1.5, due to the smaller gold nanoparticles. The worst activity and selectivity of selective oxidation of benzyl alcohol were observed for AuH1.5 catalyst, although the gold particles of AuH1.5 were a bit smaller than AuH0.5 and AuH1.0 catalysts. We attribute the worst catalytic performance of AuH1.5 to poor wormhole structure of HMS (results from Figs. 2A and $3 \mathrm{~A}$ ), which will be discussed below using the DRFIT characteristics.

The nature of active sites (Au nanoparticles) is more important. Kung's [24] opinions are that the active phase consists of an ensemble of metallic $\mathrm{Au}$ atoms and a cationic $\mathrm{Au}^{+}$species with neighboring $\mathrm{OH}$ groups. Abad et al. [17] concluded that the $\mathrm{Au}^{0}$ and $\mathrm{Au}^{+}$are essential for the selective oxidation of alcohol catalyzed by $\mathrm{Au} / \mathrm{CeO}_{2}$. They thought the introduction of oxygen into reaction system make support ceria form cerium-coordinated superoxide $(\mathrm{Ce}-\mathrm{OO})^{\bullet}$ ) species. These superoxide species evolve into cerium hydroperoxide by hydrogen abstraction from $\mathrm{Au}-\mathrm{H}$, and are responsible for the formation of the initial $\mathrm{Au}^{+}$species. Mori et al. [4] reported hydroxyapatite-supported palladium nanoclusters for selective oxidation of alcohol using molecular oxygen. The reaction mixture at $\mathrm{ca} .50 \%$ conversion was subjected to the qualitative test for $\mathrm{H}_{2} \mathrm{O}_{2}$ production. In this study, only $\mathrm{Au}^{0}$ species (no $\mathrm{Au}^{\delta+}$ species) were detected in all of Au/HMS catalysts. Support HMS was able to adsorb $\mathrm{CO}$ due to the wormhole structure and offer $\mathrm{OH}$ groups for the selective oxidation of benzyl alcohol. Surface $\mathrm{O}^{-}$species (produced from $\mathrm{OH}$ decomposition) are adsorbed on the $\mathrm{Au}^{0}$ surface, it is surface $\mathrm{O}^{-}$species on $\mathrm{Au}$ surface react with 
other oxides and produce the peroxide species (absorption band at $860 \mathrm{~cm}^{-1}$ ). Little peroxide species were observed for AuH1.5, which give the worst catalytic performance. The consumption of $\mathrm{OH}$ groups was admitted and the replenishment of $\mathrm{OH}$ groups from $\mathrm{H}_{2} \mathrm{O}$ during the reaction. Thus, negative intensity at $1630 \mathrm{~cm}^{-1}$ was observed in all of curves in DRIFT spectra. The activity of IMAuH catalyst increased with the reaction temperature, and the consumed amount of $\mathrm{H}_{2} \mathrm{O}$ increased. It is further proved that the decomposition of $\mathrm{H}_{2} \mathrm{O}$ to $\mathrm{OH}$ is benefit for the reaction. We suggested that the wormhole structure of HMS and OH groups from support HMS were useful for this reaction. The poor structure of AuH1.5 was explained for the worst catalytic performance of selective oxidation of benzyl alcohol. According to the research of Rossi et al. [25], the hydrogen peroxide was decomposed to $\mathrm{H}_{2} \mathrm{O}$ because of the basic medium. In the selective oxidation of benzyl alcohol, the added into base solution is benefit for $\mathrm{H}_{2} \mathrm{O}$ formation, and makes reaction activity of catalysts increased.

\section{Conclusion}

The selective oxidation of benzyl alcohol over Au/HMS catalysts prepared by impregnation method and direct synthesis method was studied. The Au/HMS catalyst prepared by impregnation method was found to be the most active among the investigated catalysts. The activities of Au/HMS catalysts were related to size of gold nanoparticles and wormhole structure of support HMS. Small gold nanoparticles contributed to the high activity of IMAuH catalyst. The wormhole structure of HMS is benefit for increase of the catalysts' activities and selectivities, and $\mathrm{OH}$ groups on HMS decomposed to surface $\mathrm{O}^{-}$species are essential for oxidation reaction. Surface $\mathrm{O}^{-}$adsorbed on $\mathrm{Au}^{0}$ and reacted with other oxides to the formation of peroxide species. These peroxide species are good for the selective oxidation of benzyl alcohol. The presence of base was found to be essential for activity of supported gold catalysts, which might promote the formation of $\mathrm{H}_{2} \mathrm{O}$ molecular and increased activity of catalysts in the reaction.

\section{Acknowledgements}

This work is financially supported by National Natural Science Funds for Distinguished Young Scholar (20725723), National Basic Research Program of China (2010CB732300) and the National
High Technology Research and Development Program of China (2006AA06A310).

\section{References}

[1] M. Hudlicky, Oxidation in Organic Chemistry, American Chemical Society, Washinton, DC, 1990

[2] R.J. Highet, W.C. Wildman, J. Am. Chem. Soc. 77 (1955) 4399.

[3] J.R. Holum, J. Org. Chem. 26 (1961) 4814.

[4] K. Mori, T. Hara, K. Mizugaki, K. Ebitani, K. Kaneda, J. Am. Chem. Soc. 126 (2004) 10657.

[5] B. Karimi, S. Abedi, J.H. Clark, V. Budarin, Angew. Chem. Int. Ed. 45 (2006) 4776

[6] N. Jamwal, M. Gupta, S. Paul, Green Chem. 10 (2008) 999.

[7] I.E. Marko, P.R. Giles, M. Tsukazaki, S.M. Brown, C.J. Urch, Science 274 (1996) 2044.

[8] I.E. Marko, P.R. Giles, M. Tsukazaki, I. Chelle-Regnaut, A. Gautier, S.M. Brown, C.J. Urch, J. Org. Chem. 64 (1999) 2433.

[9] K. Yamaguchi, N. Mizuno, Angew. Chem. Int. Ed. 41 (2002) 4538

[10] K. Yamaguchi, N. Mizuno, Chem. Eur. J. 9 (2003) 4353.

[11] A. Dijksman, A. Marino-González, A.M. i Payeras, I.W.C.E. Arends, R.A. Sheldon, J. Am. Chem. Soc. 123 (2001) 6826.

[12] S. Biella, M. Rossi, Chem. Commun. (2003) 378.

[13] L. Prati, M. Rossi, J. Catal. 176 (1998) 552.

[14] C. Milone, R. Ingoglia, A. Pistone, G. Neri, S. Galvagno, Catal. Lett. 87 (2003) 201.

[15] S. Carretin, P. MaMorn, P. Johnston, K. Griffin, G.J. Hutchings, Chem. Commun. (2002) 696.

[16] S. Biella, L. Prati, M. Rossi, J. Catal. 206 (2002) 242.

[17] A. Abad, P. Concepción, A. Corma, H. García, Angew. Chem. Int. Ed. 44 (2005) 4066 .

[18] A. Abad, A. Corma, H. García, Pure Appl. Chem. 79 (2007) 1847.

[19] M. Daturi, E. Finocchio, C. Binet, J.-C. Lavalley, F. Fally, V. Perrichon, H. Vidal, N. Hickey, J. Kašpar, J. Phys. Chem. B 104 (2000) 9186.

[20] T.R. Pauly, T.J. Pinnavaia, Chem. Mater. 13 (2001) 987.

[21] Y. Mori, T.J. Pinnavaia, Chem. Mater. 13 (2001) 2173.

[22] A. Stephen, K. Hashmi, G.J. Hutchings, Angew. Chem. Int. Ed. 45 (2006) 7896

[23] J.J. Zhu, J.L. Figueiredo, J.L. Faria, Catal. Commun. 9 (2008) 2395.

[24] H.H. Kung, M.C. Kung, C.K. Costello, J. Catal. 216 (2003) 425.

[25] M. Comotti, C.D. Pina, E. Falletta, M. Rossi, Adv. Synth. Catal. 348 (2006) 313.

[26] Z.H. Suo, C.Y. Ma, M.S. Jin, T. He, L.D. An, Catal. Commun. 9 (2008) 2187.

[27] K.S.W. Sing, D.H. Evrett, R.A.W. Haul, L. Moscou, R.A. Pierotti, J. Rouqérol, T. Siemieniewska, Pure Appl. Chem. 57 (1985) 603.

[28] T.A. Zepeda, J.L.G. Fierro, B. Pawelec, R. Nava, T. Klimova, G.A. Fuentes, T. Halachev, Chem. Mater. 17 (2005) 4062.

[29] M.A. Centeno, K. Hadjiivanov, Tz. Venkov, Hr. Klimev, J.A. Odriozola, J. Mol. Catal. A 252 (2006) 142.

[30] G. Avgouropoulos, M. Manzoli, F. Boccuzzi, T. Tabakova, J. Papavasiliou, T. Ioannides, V. Idakiev, J. Catal. 256 (2008) 237.

[31] B.-K. Chang, B.W. Jang, S. Dai, S.H. Overbury, J. Catal. 236 (2005) 392.

[32] D. Gamarra, A. Martínez-Arias, J. Catal. 263 (2009) 189

[33] J.J. Li, X.Y. Xu, Z.P. Hao, W. Zhao, J. Porous Mater. 15 (2008) 163.

[34] C.-T. Chang, B.-J. Liaw, Y.-P. Chen, Y.-Z. Chen, J. Mol. Catal. A 300 (2009) 80. 